\title{
Empowering High School Students Through Engagement in a Community Event
}

\author{
Steven J. Palazzo ${ }^{1}$, Ella Sanman ${ }^{1,2}$ \& Laura E. Bicknell ${ }^{1,3}$ \\ ${ }^{1}$ Seattle University, College of Nursing, USA \\ ${ }^{2}$ Virginia Mason Medical Center, USA \\ ${ }^{3}$ Seattle Children's Hospital, USA \\ Correspondence: Steven J. Palazzo, Seattle University, 901 12th Ave, Seattle, WA 98122, USA. Tel: \\ 206-406-7199. E-mail: palazzos@seattleu.edu
}

Received: April 11, 2019

doi:10.5539/ies.v12n8p83
Accepted: May 21, 2019 Online Published: July 29, 2019

URL: https://doi.org/10.5539/ies.v12n8p83

\begin{abstract}
Background: Obesity continues to afflict adolescents in underserved communities. It is difficult to understand how adolescents perceive empowerment over their health and the health of their communities. The purpose of our study was to describe the impact of the Healthy Heart Ambassador program on adolescents' perceived empowerment through the development and implementation of a community event.

Methods: High school students designed and implemented a cardiovascular health promotion and disease prevention community event using knowledge acquired through participation in the Teen Take Heart program. The HHA program was created based on the Adolescent Empowerment Model, where participants chose a community event they felt would best deliver the cardiovascular health promotion and disease prevention information. Participants completed a post event survey to evaluate their sense of empowerment while participating in the program.

Results: The AES addressed two domains and six attributes of psychological empowerment. The results suggest a sense of empowerment resulted from participating in the student-led community event.

Conclusion: During the HHA event students were engaged with other students, teachers, and members of their community who attended the event. In addition, groups of students who did not normally interact with each other were cooperating and working as a team.
\end{abstract}

Keywords: empowerment, education, community, engagement, high school, adolescents

\section{Introduction}

In response to the need for improved cardiovascular health education in communities lacking resources, the Hope Heart Institute (a not for profit organization based in Bellevue, Washington) collaborated with the College of Nursing at Seattle University to develop, implement, and evaluate a cardiovascular health promotion and disease prevention program, Teen Take Heart (TTH). In addition to the learning modules associated with TTH, graduate students in the College of Nursing along with the Director of the TTH program created an additional component of the TTH program, the Healthy Heart Ambassador program (HHA). This program aimed to provide high school students an opportunity to share what they learned in the TTH program with family, peers, and community members through a student-led community outreach program.

An established model of teen empowerment was used as a framework to develop the HHA program. The HHA program provided a mechanism for students to extend their classroom learning experience to their community in a community-specific way; considering the needs of their community. A post-project instrument, the Adolescent Empowerment Survey (AES), was administered to measure the continuity of student participation and students' perceived ability to make positive change.

\subsection{The Teen Take Heart Program}

Teen Take Heart (TTH) is a four-module, 18-lesson, interactive web- and kit-based cardiovascular curriculum for teenagers at risk for cardiovascular disease (Palazzo, 2017). Each module focuses on a different aspect of cardiovascular health. The modules cover structure and function, cardiovascular diseases, nutrition and activity, 
and principles of scientific inquiry (Palazzo, 2019). Teen Take Heart seeks to develop positive attitudes (beliefs) about health and wellness, create a learning environment emphasizing health promotion as a cultural norm, and encourages students to take control over their health through behavioral change (Palazzo, 2019).

Cardiovascular disease is the nation's leading cause of death, and the burden falls disproportionately on underserved communities (CDC: Heart Disease Facts and Statistics, 2019). Cardiovascular health is a multifaceted health outcome involving a complex interplay of social determinants, including cultural, genetic, and economic factors. This makes cardiovascular health a complicated and difficult metric to measure and change.

Obesity is a known risk factor for the development of cardiovascular disease, and it has risen to crisis levels among children and adolescents. In 2016-17, an estimated 14.8\% of high school students were obese and only $26.1 \%$ met physical activity guidelines (Health Resources and Services Administration, Maternal and Child Health Bureau. National Survey of Children's Health, 2018). Additionally, 38.1\% of adults in the United States are obese (The State of Obesity, 2018).

In 2010, the American Heart Association (AHA) defined cardiovascular health according to ideal health behaviors and ideal health factors (Table 1). Over $30 \%$ of adolescents are not meeting the ideal body mass index standard and zero percent of adolescents are meeting the ideal diet score (Shay et al., 2001). There is evidence that suggests obese adolescents become obese adults (Wright, Parker, Lamont, \& Craft, 2001). Since cardiovascular disease processes begin in childhood and manifest in late adulthood, adolescence provides a critical timeframe and important opportunity to intervene (Berenson et al., 1992; McNamara, Molot, Stemple, \& Cutting, 1971; Zieske, Malcom, \& Strong, 2002). Targeted and effective interventions that empower adolescents to be change agents in their communities are needed.

Table 1. Definitions of Poor, Intermediate, and Ideal Cardiovascular Health as defined by the American Heart Association 2020 Goals for Children 12-19 years of age (Lloyd-Jones et al., 2010)

\begin{tabular}{|c|c|c|c|}
\hline Metric & Poor & Intermediate & Ideal \\
\hline Blood Pressure & $>95^{\text {th }}$ percentile & $\begin{array}{l}90-95^{\text {th }} \text { percentile or } \mathrm{SBP} \geq 120 \\
\mathrm{mmHg} \text { or } \mathrm{DBP} \geq 80 \mathrm{mmHg}\end{array}$ & $<90^{\text {th }}$ percentile \\
\hline Physical Activity & none & $\begin{array}{l}>0 \text { and }<60 \mathrm{~min} \text { of moderate or } \\
\text { vigorous physical activity } \\
\text { everyday }\end{array}$ & $\begin{array}{l}>60 \text { minutes of mod or } \\
\text { vigorous physical activity } \\
\text { daily }\end{array}$ \\
\hline Total cholesterol & $>=200 \mathrm{mg} / \mathrm{dL}$ & $170-199 \mathrm{mg} / \mathrm{dL}$ & $<170 \mathrm{mg} / \mathrm{dL}$ \\
\hline $\begin{array}{l}\text { Healthy diet score }(\geq 4.5 \text { cups of fruits } \& \\
\text { vegetables per day, } \geq \text { two } 3.5 \mathrm{oz} \text { servings of fish } \\
\text { per week, } \geq \text { three } 1 \mathrm{oz} \text { servings of fiber rich } \\
\text { whole grains per day, }<1500 \mathrm{mg} \text { per day of } \\
\text { sodium, and } \leq 450 \mathrm{kcal} \text { per week of } \\
\text { sugar-sweetened beverages) }\end{array}$ & $0-1$ components & $2-3$ components & 4-5 components \\
\hline BMI & $>95^{\text {th }}$ percentile & $85-95^{\text {th }}$ percentile & $<85^{\text {th }}$ percentile \\
\hline Smoking status & Tried prior 30 days & & $\begin{array}{l}\text { Never tried; never smoked } \\
\text { whole cigarette }\end{array}$ \\
\hline Fasting plasma glucose & $126 \mathrm{mg} / \mathrm{dL}$ or more & $100-125 \mathrm{mg} / \mathrm{dL}$ & $<100 \mathrm{mg} / \mathrm{dL}$ \\
\hline
\end{tabular}

Teenagers are effective community liaisons for educating family, friends, and peers about health-related matters. They have been called the "new generation" of lifesavers because of their willingness and ability to perform CPR, as well as for their potential years of service (Cave, 2011; Fleischhackl et al., 2009). Stanford University offered a crash course to train high school students to be High School Sleep Ambassadors (Training Teens," 2016) and the Chicago Department of Health through its Teen Outreach Program sought to use peer-to-peer education as a means of preventing teenage pregnancy (Office of Adolescent Health, 2019). These programs successfully used adolescents as community liaisons to disseminate information and create change in their communities.

\subsection{The Healthy Heart Ambassador Program}

Upon completion of the TTH program high school students receive a certificate designating them as a Healthy Heart Ambassador (HHA); eligible to volunteer in the HHA program. The HHA program provides an 
opportunity for high school students to disseminate knowledge about cardiovascular health acquired during their participation in the Teen Take Heart (TTH) program to their community through planning, organizing, and implementing a community event. Students are encouraged to choose an event that is unique and relevant to their community in which to disseminate knowledge about cardiovascular health promotion and disease prevention. Examples of program events include a cardiovascular education family night, a community $5 \mathrm{~K}$ run/walk, peer teaching, trivia night, or an educational booth at a health or science fair. Typically, a month is required to plan, organize, and implement the community event.

Healthy Heart Ambassador participants meet during designated times with an adult facilitator(s) from their high school. The adult facilitator(s) is the person(s) responsible for implementing and leading the HHA program at the high school. The facilitator is typically a teacher participating in the TTH program but could be another leader from the community. There can be more than one facilitator for the HHA team. The facilitator's primary role is to monitor program progression, role model professional behaviors, and guide team processes.

The Healthy Heart Ambassador Program Community Event Manual guides the facilitator through the process of leading a group of high school students in the design and implementation of a community event. Upon completion of the HHA program, students take the Adolescent Empowerment Survey (AES), a post-project survey that measures their participation and perceptions about their ability to make positive changes in their community (empowerment).

\subsection{Adolescent Empowerment}

The HHA program uses the Adolescent Empowerment Model (AEM) as a framework for adolescent empowerment. Researchers developed the AEM by merging themes from identity development and bonding theories from psychologists such as Erik Erikson and James Marcia (Chinman \& Linney, 1998). It outlines a process in which adolescents participate in positive voluntary experiences that in turn, help to enhance their self-esteem, self-efficacy, positive role choice, and positive identity formation (Chinman \& Linney, 1998).

Adolescence is a time of rapid change and development. Five core cognitive changes occur during adolescents: ability to think about what is possible, consider abstract ideas, metacognition, multidimensional thinking, and viewing things as relative versus absolute (Steinberg, 2001). In addition to these cognitive changes, significant physical, sexual, social, and emotional transitions take place. Erik Erikson, a prominent psychologist who has made significant contributions to developmental psychology, theorized that a creating a coherent sense of identity is the main task undertaken during adolescence. Throughout adolescence, teenagers go through phases as they experiment with roles, personalities, and responsibilities (Steinberg, 2001). The vast amount of transition that occurs during adolescence makes it a critical time for individuals to realize their potential and influence over themselves and others.

The pivotal psychological changes occurring in adolescence provide an opportunity to intervene and help adolescents overcome adversity and make successful transitions to adulthood (Morton \& Montgomery, 2013). Since the 1980s, researchers have been trying to identify intervention strategies that are successful for the adolescent population. Researchers suggests that trying to prevent something negative from happening to youth (i.e. the risk-factor paradigm), which has been the focus of the drug prevention field since the $1960 \mathrm{~s}$, might not be the best strategy and that the focus should be on positive youth development via youth empowerment which provides opportunities that reinforce and nourish thriving instead of decreasing access to the challenges and high-risk behavior they might encounter (Scales \& Benson, 2011).

The Adolescent Empowerment Model (AEM) was used for the development of the HHA program because studies on the effects of interventions that include the positive participatory components of the empowerment model have demonstrated positive outcomes. The results from three studies that used the AEM suggest that when youth participate in meaningful roles, learn new skills, and are recognized for their involvement, they had enhanced self-esteem, self-efficacy, positive role choice, and positive identity formation (Allen, Philliber, \& Hoggeson, 1990; Calabrese \& Schumer, 1986; Zimmerman \& Maton, 1992).

The HHA program incorporates elements of the AEM that provide adolescents the opportunity to assume a leadership role in the development and implementation of their own community event. The facilitator guides students to fulfill one of the following group roles: leader, secretary, scouter, checker, or encourager. The facilitator challenges the students to identify the barriers their family, friends, and communities have that imped their living a more heart healthy lifestyle. Participating students enter their community to collect and synthesize the knowledge of their community members. Participants use this information along with the knowledge gained from participation in the TTH program to develop a community specific event. Since the HHA team are responsible for choosing and overseeing the community event, it is hypothesized that they will strengthen and 
develop new skills such as leadership, professional communication, and organization, which have been associated with empowerment.

The purpose of our program evaluation is to describe the impact of the HHA program on adolescents' perceived empowerment through the development and implementation of a community event. The Adolescent Empowerment Survey (AES) was used to describe adolescent empowerment after participating in the HHA program and facilitation of the community event.

\section{Methods}

\subsection{Program Overview}

The university's IRB committee granted exemption status for this study. Enrolled subjects submitted to the PI a signed assent form indicating their understanding of the study and that they delivered to and reviewed a passive parental permission form with their parent(s) or guardian. Parent(s) or guardians had the option of contacting the PI via email or telephone to opt their adolescent out of the study. No student identifiers were collected in the survey evaluating the HHA program. There was no link between the TTH survey data and HHA survey data. Student characteristics are described in Table 2. At the time of the study, all the authors had completed CITI training.

Table 2. Modified adolescent empowerment survey demographics

\begin{tabular}{ll}
\hline & Percent (n) \\
\hline Age-mean & 16.7 \\
15 & $11.1 \%(5)$ \\
16 & $26.7 \%(12)$ \\
17 & $40.0 \%(18)$ \\
18 & $15.6 \%(7)$ \\
19 & $2.2 \%(1)$ \\
\hline Gender & \\
Male & $33.3 \%(15)$ \\
Female & $66.7 \%(30)$ \\
\hline Grade & \\
$10^{\text {th }}$ & $6.7 \%(3)$ \\
$11^{\text {th }}$ & $31.1 \%(14)$ \\
$12^{\text {th }}$ & $62.2 \%(28)$ \\
\hline School performance & \\
Much better than average & $22.2 \%(10)$ \\
Better than average & $26.7 \%(12)$ \\
Average & $48.9 \%(22)$ \\
Below average & $2.2 \%(1)$ \\
Much worse than average & 0 \\
Don't know & 0 \\
\hline Do you plan to go to college? & \\
Yes & \\
No & $91.1 \%(41)$ \\
Don't know or undecided & 0 \\
\hline How do you describe your race or ethnicity? Select all that apply. \\
White & $22.2 \%(10)$ \\
Black/African American & $22.2 \%(10)$ \\
Hispanic/Latino/Latina & $42.2 \%(19)$ \\
Asian & $26.7 \%(12)$ \\
Pacific Islander & $4.4 \%(2)$ \\
American Indian & $4.4 \%(2)$ \\
Alaska Native & 0 \\
Multicultural & $11.1 \%(5)$ \\
Other & $6.7 \%(3)$ \\
\hline
\end{tabular}


One of the high schools participating in the TTH program during the 2014-2015 school year was selected to participate in the HHA program. The high school was in an underserved community in the Puget Sound region of Seattle, Washington. The HHA facilitator, a teacher from the participating school, received a copy of The Healthy Heart Ambassador Program Community Event Manual to guide them through options for community events. Upon successful completion of the TTH program students received a Healthy Heart Ambassador certificate and were given the option of participating in the HHA program. All the students at the participating school who went through the TTH program participated in the HHA program. These students were provided designated class time for event development of the community event. The participating students chose to create cardiovascular educational booths at a school science, art, and technology fair.

\subsubsection{Data Collection and Analysis}

The Adolescent Empowerment Survey (AES) was used to describe empowerment (Table 3). This survey is a modification (with permission from the authors) of the Youth Group Member Survey (YGMS) of Holden et al. (2005). The YGMS was evaluated for validity through prior studies (Holdern, Crankshaw, Nimsch, Hinnant, \& Hund, 2004; Holden, Messeri, Evans, Crankshaw, \& Ben-Davis, 2004; Holdern, Evans, Hinnant, \& Messeri, 2005). The YGMS was adapted to focus on cardiovascular health versus tobacco. The content of the survey was minimally changed during this process and thus the resulting AES instrument was not reanalyzed for validity.

Table 3. Modified adolescent empowerment survey questions with scale used to measure PE attributes

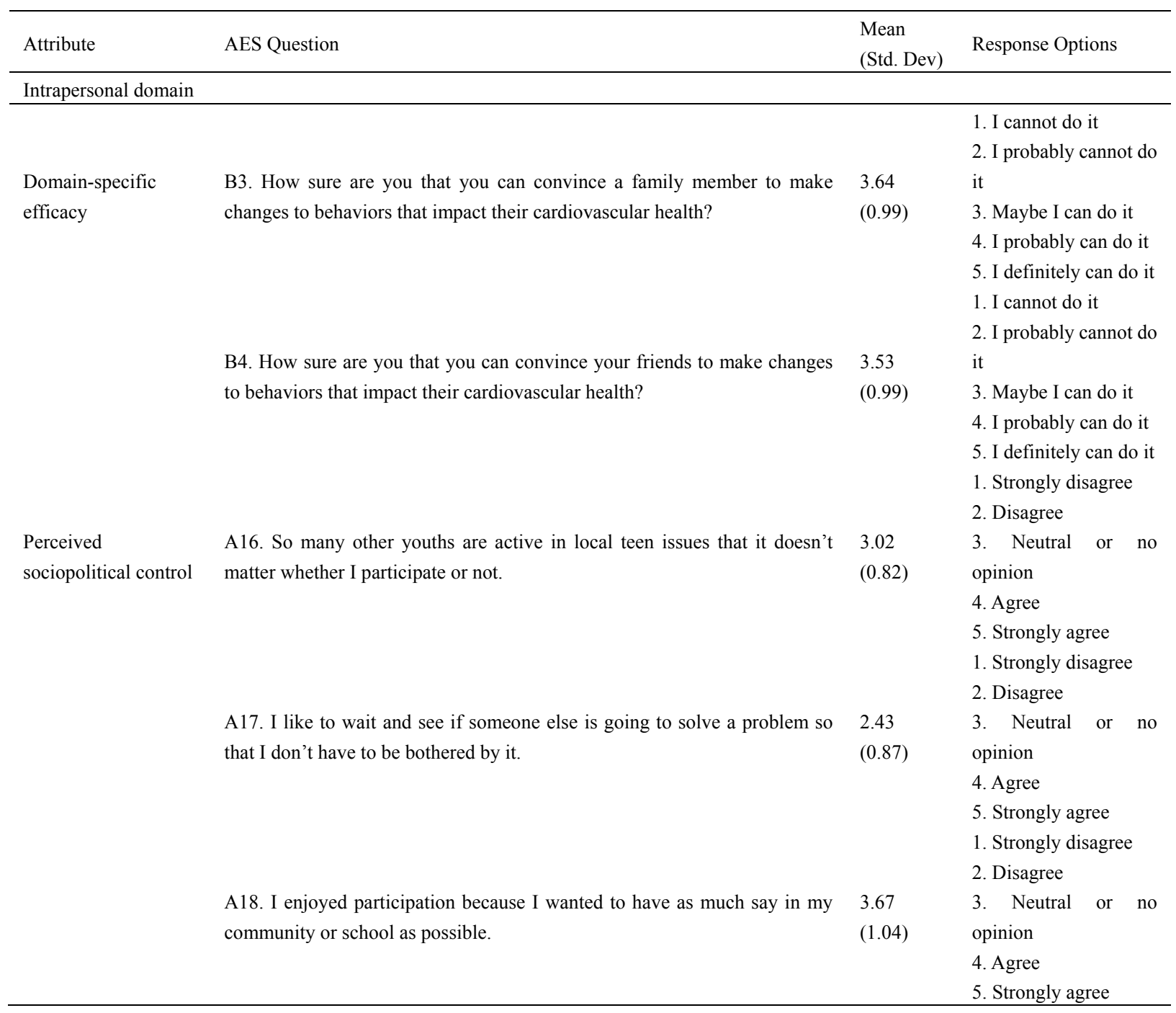


A19. I find it very hard to talk in front of this group.

Participatory competence
A25. I can work with people in this group to get things done.

A26. I can influence the decisions this group makes.
1. Strongly disagree

2. Disagree

2.38 3. Neutral or no

(1.029) opinion

4. Agree

5. Strongly agree

1. Very often

2. Often

1.91

(1.04)

3. Occasionally

4. Rarely

5. Never

6. I have not had the opportunity to do this

1. Very often

2. Often

3. Occasionally

2.36

4. Rarely

5. Never

6. I have not had the opportunity to do this
Interactional domain

Knowledge

resources
A6. What resources are available to you in your community or school to help you work on cardiovascular health education programs? Select all that apply

Access to media/news reporters for promoting events

Funding to conduct activities

Adults who believe youth can make a difference

Other people my age who want to work on cardiovascular health issues

0.40 health issues

Government or agency programs that provide training on skills for being involved

(2)

B1. I can invite others to work on cardiovascular education programs.

1. Strongly disagree

2. Disagree

3. Neutral or no opinion

4. Agree

5. Strongly agree

1. Strongly agree

2. Agree

3. Neutral or have no opinion

4. Disagree

5. Strongly disagree

1. Strongly agree

2. Agree

3. Neutral or have no

B2. I can start discussions with others, outside of this group, about 2.39 cardiovascular health.
$(0.89)$ opinion

4. Disagree

5. Strongly disagree 


\begin{tabular}{|c|c|c|c|}
\hline \multirow{10}{*}{ Advocacy } & \multirow{5}{*}{$\begin{array}{l}\text { B5. In the last year, how many times have you tried to convince other } \\
\text { students, your family, or friends to make more heart healthy choices? }\end{array}$} & \multirow{5}{*}{$\begin{array}{l}3.16 \\
(1.45)\end{array}$} & 1. Never \\
\hline & & & 2. Once \\
\hline & & & 3. 2 or 3 times \\
\hline & & & 4. 4 or 5 times \\
\hline & & & 5.6 or more times \\
\hline & \multirow{5}{*}{$\begin{array}{l}\text { B6. In the last year, how many times have you tried to convince school } \\
\text { officials, local businesses, community agencies, or government officials to } \\
\text { be more concerned about cardiovascular health? }\end{array}$} & \multirow{5}{*}{$\begin{array}{l}1.77 \\
(1.18)\end{array}$} & 1. Never \\
\hline & & & 2. Once \\
\hline & & & 3.2 or 3 times \\
\hline & & & 4. 4 or 5 times \\
\hline & & & 5.6 or more times \\
\hline
\end{tabular}

The AES is divided into three sections, which focus on different aspects of the participant's experience. Section A (26 questions) focuses on the HHA team, the role the adolescent played, and the process of change. Section B (8 questions) focuses on the impact the adolescent can have on other people about cardiovascular education. Section C (7 questions) asks participants' demographic information. The responses to these questions were described using means and standard deviations. SPSS version 22 was used for data analysis.

\section{Results}

Students from the participating high school hosted informational tables at a school festival for arts, science, and technology. The high students from the TTH program that participated in the HHA program were given class time to work on HHA program in addition to time after school. The students presented information about blood pressure, exercise, nutrition, and the structure and impact of drugs on the heart. Forty-five students $(n=45)$ participated in the HHA program and completed the AES.

Among students who reported their primary reason for participating the most frequent response was "to learn new skills" followed by "to gain more knowledge about cardiovascular health." The AES has questions that address the two domains and six attributes of psychological empowerment. The questions with relation to each domain and attribute along with the means and standard deviations are provided in Table 3 . The students in this group were very close and felt like they could communicate and work well together. The majority $(62.2 \%)$ of students responded that they disagreed or strongly disagreed with the statement "I find it very hard to talk in front of this group." In addition, the majority (80.0\%) of students responded with "very often" or "often" to "I can work with people in this group to get things done." The majority $(60.0 \%)$ of students said they often or very often "can influence the decisions this group makes." These responses indicate group cohesion.

\subsection{Participation}

Participation in HHA was measured by two questions in the AES. The two questions focused on the intensity or level of participation in the program. The first item asks about the percentage of planning meetings attended. A majority (57.8\%) of participants reported attending all meetings. When asked in the past 30 days how many total hours' participants had been involved in team activities a third (33.3\%) of the students stated that they devoted 4 to 5 hours to the team activities.

\subsection{Linear Regression Analysis}

This study aimed to see how participation in the Healthy Heart Ambassador program empowered adolescents. The participation measures noted above along with age, sex, and race were independent variables with the outcome variable in regression analysis being components of psychological empowerment. Linear regression was used for the analysis. The results of this regression analysis are presented in Table 4. 
Table 4. Linear regression results

\begin{tabular}{|c|c|c|c|c|c|c|c|c|c|c|c|c|}
\hline & \multicolumn{2}{|c|}{$\begin{array}{c}\text { Domain specific } \\
\text { efficacy }\end{array}$} & \multicolumn{2}{|c|}{$\begin{array}{c}\text { Perceived } \\
\text { sociopolitical control }\end{array}$} & \multicolumn{2}{|c|}{$\begin{array}{l}\text { Participatory } \\
\text { competence }\end{array}$} & \multicolumn{2}{|c|}{$\begin{array}{c}\text { Knowledge of } \\
\text { resources }\end{array}$} & \multicolumn{2}{|c|}{ Assertiveness } & \multicolumn{2}{|c|}{ Advocacy } \\
\hline & P Est & $\begin{array}{l}\text { Std } \\
\text { Error }\end{array}$ & P Est & $\begin{array}{l}\text { Std } \\
\text { Error }\end{array}$ & P Est & $\begin{array}{l}\text { Std } \\
\text { Error }\end{array}$ & P Est & $\begin{array}{l}\text { Std } \\
\text { Error }\end{array}$ & P Est & $\begin{array}{l}\text { Std } \\
\text { Error }\end{array}$ & P Est & $\begin{array}{l}\text { Std } \\
\text { Error }\end{array}$ \\
\hline Age & -.136 & .370 & $-.964 *$ & .494 & $.644^{*}$ & .352 & -.019 & .268 & $-.566^{* *}$ & .272 & .134 & .391 \\
\hline Male & .782 & .721 & .564 & .964 & .369 & .687 & $.964 *$ & .522 & .817 & .531 & $1.641^{* *}$ & .763 \\
\hline Hispanic/Latino & $-1.569^{*}$ & .890 & -.493 & 1.189 & $1.477^{*}$ & .848 & -.375 & .644 & $-1.506^{* *}$ & .655 & $-1.690 *$ & .941 \\
\hline $\begin{array}{c}\text { Other race } \\
100 \%\end{array}$ & $-1.883^{*}$ & .979 & -1.295 & 1.309 & .995 & .933 & -.158 & .709 & $-2.127 * *$ & .721 & $-1.986^{*}$ & 1.036 \\
\hline $\begin{array}{c}\text { attendance at } \\
\text { events }\end{array}$ & .088 & .640 & -.152 & .856 & -.282 & .610 & -.279 & .464 & -.149 & .471 & $1.667 * *$ & .677 \\
\hline $\begin{array}{c}\text { Four or more } \\
\text { hours spent on } \\
\text { event }\end{array}$ & -.391 & .701 & -1.299 & .937 & .603 & .668 & .392 & .508 & -.753 & .516 & -.751 & .742 \\
\hline $\begin{array}{c}\text { Held formal } \\
\text { leadership role }\end{array}$ & .151 & 1.096 & 1.595 & 1.464 & -.276 & 1.044 & .898 & .794 & .754 & .807 & -.206 & 1.159 \\
\hline $\begin{array}{c}\text { Takes part } \\
\text { discussion often } \\
\text { or very often }\end{array}$ & 1.043 & .687 & .904 & .918 & .470 & .654 & .078 & .497 & -.025 & .506 & -.878 & .726 \\
\hline $\begin{array}{c}\text { Encourages } \\
\text { other to } \\
\text { participate often } \\
\text { or very often }\end{array}$ & .188 & .734 & -.477 & .981 & .321 & .699 & .035 & .532 & -.509 & .540 & $1.865^{* *}$ & .777 \\
\hline $\begin{array}{c}\text { Takes } \\
\text { responsibility to } \\
\text { get things done } \\
\text { often or very } \\
\text { often }\end{array}$ & .342 & .649 & -.329 & .868 & $1.089^{*}$ & .618 & .403 & .470 & $-1.123^{* *}$ & .478 & -.303 & .687 \\
\hline
\end{tabular}

* significant at $\mathrm{p}<0.10$ level; ** significant at $\mathrm{p}<0.05$ level.

\subsubsection{Domain Specific Efficacy}

Domain specific efficacy was assessed using two questions which asked about the ability to convince family members or friends to makes changes in behavior to improve cardiovascular health. Race was found to be associated with domain specific efficacy. Hispanic/Latino/Latina and non-white participants were significantly less likely to report domain specific efficacy $(\mathrm{p}<.10)$.

\subsubsection{Perceived Sociopolitical Control}

Perceived sociopolitical control was assessed through four questions about involvement and engagement with the group. Age was associated with decreased perceived sociopolitical control $(\mathrm{p}<.10)$.

\subsubsection{Participatory Competence}

Participatory competence was measured with two questions. The first of which was "I can work with people in this group to get things done" and the second was "I can influence the decisions this group makes." Age, Hispanic/Latino/Latina were associated with increased participatory competence $(\mathrm{p}<.10)$.

\subsubsection{Knowledge of Resources}

Participants knowledge of resources was measured through one question which asked "What resources are available to you in your community or school to help you work on cardiovascular health education programs" with multiple response options. Male gender was associated with increased knowledge of resources $(p<.10)$.

\subsubsection{Assertiveness}

Assertiveness was measured by three questions which gauge participants' interaction and involvement with others outside of the group. Age, Hispanic/Latino/Latina, non-white race, and taking responsibility to get things done often or very often were all negatively, associated with assertiveness $(p<.05)$.

\subsubsection{Advocacy}


Two questions measured advocacy in the AES survey. The questions focused on how many times participants had tried to convince other members of their community, school, or local government to make healthy choices or be concerned about cardiovascular health. Male gender, attending $100 \%$ of meetings or events, and encouraging others to participate in the event often or very often were predictors of advocacy $(\mathrm{p}<.05)$. Hispanic/Latino/Latina and non-white participants were associated with lower advocacy $(\mathrm{p}<.10)$.

The quality of participation and roles played by HHA participants was measured by three questions. Students self-reported their roles, including formal leadership. $13.3 \%$ of participant's report serving a formal leadership role, such as holding an office or leading a committee. $46.7 \%$ of participant's report participating in discussion often or very often when they attended meetings. Additionally, $51.1 \%$ of participant's report trying to encourage other to attend the HHA event often or very often.

\section{Discussion}

The quantity and quality of participation in the HHA program affected the components of adolescent empowerment. The components of empowerment among students were enhanced through participation in the HHA program. The overall observed outcomes of the HHA program were extremely positive. During the HHA event students were engaged with other students, teachers, and members of their community who attended the event. In addition, groups of students who did not normally interact with each other were cooperating and working as a team to create jump rope games at the exercise table.

The HHA leader, other teachers, and administrators from the school provided positive feedback about the information and delivery provided by the HHA participants. A representative from the Office of Superintendent of Public Instruction for Washington State said, "Several now have interests in going further in their studies after high school. It was amazing to see the students jumping rope at lunch time and to see them standing by their displays readily explaining what their stations were about."

Hispanic/Latina/Latino and other participants had decreased domain specific efficacy, assertiveness, and advocacy. Hispanic/Latina/Latino participants had increased participatory competence. The research this study was modeled after did not find race to be associated with any elements of psychological empowerment (Holden, Crankshaw, Nimsch, Hinnant, \& Hund, 2004). The linkage between race and components of psychological empowerment is a pathway which further research is needed to determine the effect educational structures and systems have on student empowerment.

The small sample size $(n=45)$ and inclusion of one high school greatly limits the generalizability of the results. The modified AES was not validated as a survey instrument for evaluating empowerment and this could limit the reliability of results. This was a post-test-only design, so we could not measure change.

\section{Conclusion}

Recommended next research steps include implementation of the programs (TTH and HHA) in multiple schools and with different community events to evaluate if the type of community event affects participation and outcomes. In addition, the AES survey could be adapted to become more streamlined and concise to increase quality of responses. We observed that students grew impatient at answering all the questions on the current survey. A pretest posttest design would clarify the impact of change on students' perceived levels of engagement and empowerment.

By empowering adolescents and decreasing risk factors overall health outcomes improve, such as decreased disease prevalence and health care costs. As further research is conducted it is likely the link between adolescent empowerment and knowledge, attitudes and behaviors will be strengthened. Nurses and advance practice nurses can support adolescents as they develop and guide them to community resources, activities, and empowering opportunities, which incorporate and develop intrapersonal, interactional and behavioral components of the psychological empowerment model. Empowered adolescents will gain control over outcomes and change within their own lives and communities as they develop healthy habits into adulthood.

The ultimate measure of success is long-term changes in behavior that lead to reduced cardiovascular risk and better health outcomes in the community. Longitudinal studies involving large numbers of student ambassadors and community members could help determine the effect and sustainability of the outreach efforts initiated by the HHA program. We hope this article will encourage others to implement health behavior programs and conduct studies to test the effects of purposeful engagement and empowerment among students, teachers, parents, and communities. 


\section{Statement of Conflict of Interest}

We want to confirm that there are no known conflicts of interest associated with this manuscript nor has there been any significant financial support that could have influenced the perspectives shared in this paper. All the named authors have made substantial contributions to the manuscript and have approved of this version being submitted. This manuscript has not been submitted elsewhere.

\section{Acknowledgements}

Robert Wood Johnson Foundation, Nurse Faulty Scholar's program, award \#71248.

\section{References}

Allen, J. P., Philliber, S., \& Hoggson, N. (1990). School-based prevention of teen-age pregnancy and school dropout: process evaluation of the national replication of the Teen Outreach Program. American journal of community psychology, 18(4), 505-524. https://doi.org/10.1007/bf00938057

Berenson, G. S., Wattigney, W. A., Tracy, R. E., Newman III, W. P., Srinivasan, S. R., Webber, L. S., ... \& Strong, J. P. (1992). Atherosclerosis of the aorta and coronary arteries and cardiovascular risk factors in persons aged 6 to 30 years and studied at necropsy (The Bogalusa Heart Study). The American journal of cardiology, 70(9), 851-858. https://doi.org/10.1016/0002-9149(92)90726-f

Calabrese, R. L., \& Schumer, H. (1986). The effects of service activities on adolescent alienation. Adolescence, 21(83), 675-687.

Cave, D. M., Aufderheide, T. P., Beeson, J., Ellison, A., Gregory, A., Hazinski, M. F., ... \& Nadkarni, V. (2011). Importance and implementation of training in cardiopulmonary resuscitation and automated external defibrillation in schools: a science advisory from the American Heart Association. Circulation, 123(6), 691-706. https://doi.org/10.1161/cir.0b013e31820b5328

Centers for Disease Control and Prevention (CDC). (2019). Heart disease facts \& statistics. Retrieved May 18, 2019 from http://www.cdc.gov/heartdisease/facts.htm

Chinman, M. J., \& Linney, J. A. (1998). Toward a model of adolescent empowerment: Theoretical and empirical evidence. Journal of Primary Prevention, 18(4), 393-413. https://doi.org/10.1023/A:1022691808354

Fleischhackl, R., Nuernberger, A., Sterz, F., Schoenberg, C., Urso, T., Habart, T., ... \& Chandra-Strobos, N. (2009). School children sufficiently apply life supporting first aid: A prospective investigation. Critical Care, 13(4), R127. https://doi.org/10.1186/cc7984

Health Resources and Services Administration, Maternal and Child Health Bureau. (2018). National Survey of Children's Health. Retrieved from https://mchb.hrsa.gov/data/national-surveys

Holden, D. J., Crankshaw, E., Nimsch, C., Hinnant, L. W., \& Hund, L. (2004). Quantifying the impact of participation in local tobacco control groups on the psychological empowerment of involved youth. Health Education \& Behavior, 31(5), 615-628. https://doi.org/10.1177/1090198104268678

Holden, D. J., Evans, W. D., Hinnant, L. W., \& Messeri, P. (2005). Modeling psychological empowerment among youth involved in local tobacco control efforts. Health Education \& Behavior, 32(2), 264-278.https://doi.org/10.1177/1090198104272336

Holden, D. J., Messeri, P., Evans, W. D., Crankshaw, E., \& Ben-Davies, M. (2004). Conceptualizing youth empowerment within tobacco control. Health Education \& Behavior, 31(5), 548-563. https://doi.org/10.1177/1090198104268545

Levi, J., Segal, L., Martin, A., \& Rayburn J. (2014). The State of Obesity: Better Policies for a Healthier America. References from http://www.rwjf.org/en/library/research/2014/09/the-state-of-obesity.html

McNamara, J. J., Molot, M. A., Stremple, J. F., \& Cutting, R. T. (1971). Coronary artery disease in combat casualties in Vietnam. Jama, 216(7), 1185-1187. https://doi.org/10.1001/jama.1971.03180330061012

Morton, M. H., \& Montgomery, P. (2013). Youth empowerment programs for improving adolescents' self-efficacy and self-esteem a systematic review. Research on Social Work Practice, 23(1), 22-33. https://doi.org/10.1177/1049731512459967

Office of adolescent health. (2019). About Teen Pregnancy Prevention (TPP) Program. Retrieved from https://www.hhs.gov/ash/oah/grant-programs/teen-pregnancy-prevention-program-tpp/about/index.html

Palazzo, S. J. (2017). Teen Take Heart: A Pilot Intervention to Improve High School Students' Behavioral Intentions to Engage in Physical Activity and Better Nutrition. Journal of Adolescent Health, 60(2), S65. 
https://doi.org/10.1016/j.jadohealth.2016.10.312

Palazzo, S. J. (2019). Teen Take Heart. Retrieved May 18, 2019 from https://www.teentakeheart.org

Palazzo, S., Skager, C., \& Kraiger, A. (2014). Describing an academic and nonprofit organization partnership to educate at-risk adolescents about cardiovascular health. Education, 135(1), 51-58.

Scales, P. C., \& Benson, P. L. (2011). Adolescent thriving: the role of sparks, relationships, and empowerment. Journal of Youth Adolescence, 40(3), 263-77. https://doi.org/10.1007/s10964-010-9578-6

Shay, C. M., Ning, H., Daniels, S. R., Rooks, C. R., Gidding, S. S., \& Lloyd-Jones, D. M. (2013). Status of cardiovascular health in US adolescents: prevalence estimates from the National Health and Nutrition Examination Surveys (NHANES) 2005-2010. Circulation, 127(13), 1369-1376. https://doi.org/10.1161/circulationaha.113.001559

Steinberg, L. (2001). Adolescence. In B. R. Strickland (Ed.), The Gale Encyclopedia of Psychology (pp. 11-15). Detroit, MI: Gale.

Wright, C. M., Parker, L., Lamont, D., \& Craft, A. W. (2001). Implications of childhood obesity for adult health: findings from thousand families cohort study. Bmj, 323(7324), 1280-1284. https://doi.org/10.1136/bmj.323.7324.1280

Zieske, A. W., Malcom, G. T., \& Strong J. P. (2002). Natural history and risk factors of atherosclerosis in children and youth: the PDAY study. Fetal \& Pediatric Pathology, 21(2), 213-237. https://doi.org/10.1080/pdp.21.2.213.237

Zimmerman, M. A., \& Maton, K. I. (1992). Life-style and substance use among male African American urban adolescents: A cluster analytic approach. American Journal of Community Psychology, 20(1), 121-138. https://doi.org/10.1007/bf00942184

\section{Copyrights}

Copyright for this article is retained by the author(s), with first publication rights granted to the journal.

This is an open-access article distributed under the terms and conditions of the Creative Commons Attribution license (http://creativecommons.org/licenses/by/4.0/). 